\title{
Kecerdasan Intelektual, Kecerdasan Emosional, Kecerdasan Spiritual Dan Organizational Citizenship Behavior Terhadap Kinerja Pegawai
}

\author{
Mawar Ratih, 1) Brahma Wahyu, ${ }^{2)}$ Bambang Suwarsono ${ }^{3)}$ \\ Universtias Islam Kadiri Kediri 1,2,3) \\ Email: mawarratih@uniska-kediri.ac.id
}

\author{
Received: 09 May 2021; Revised: 26 July 2021; Accepted: 28 August 2021 \\ DOI: http://dx.doi.org/10.37905/aksara.7.3.1263-1272.2021
}

\begin{abstract}
Performance is the one thing to measure succesul of an organization. Effort to Improve the performance its very important to achieved organization goal. Efforts to improve performance are not easy to achieve because it is influenced by many factors including factors that come from the employees itsself likes intellectual quotients, emotional quotients, spiritual quotients and organizational citizenship behavior. These factors are very important to noticed, they are expected to make more contribute to improving performance. This research was conducted all 71employees of the General Section of the Regional Secretariat of the City of Kediri. Data was obtained through observation, interviews and questionnaires. This study uses multiple linear regression analysis, with the results obtained: intellectual quotients (IQ) does not partially affect employee performance, emotional quotients (EQ) partially affects employee performance, spiritual quotients (SQ) does not affect partially partially on employee performance, organizational citizenship behavior $(O C B)$ has a partial influence on employee performance, and simultaneously intellectual quotients (IQ), emotional quotients (EQ), spiritual quotients $(S Q)$ and organizational citizenship behavior $(O C B)$ affect employee performance.
\end{abstract}

Keywords: Intellectual Quotients (IQ), Emotional Quotients (EQ), Spiritual Quotients $(S Q)$, Organizational Citizenship Behavior (OCB), Performance .

\section{PENDAHULUAN}

Keberhasilan suatu organisasi ditentukan oleh seberapa besar keberhasilan organisasi dalam mewujudkan tujuannya. Demi mewujudkan hal tersebut maka organisasi wajib mengoptimalkan kinerja, hal tersebut bisa dilakukan jika organisasi disokong oleh sumber daya manusia yang berkompeten. Sumber daya manusia yang berkompeten bisa dinilai dari kemampuan, keahlian, kecakapan dan juga bisa dilihat dari bagaimana penguasaan dan pengelolaan diri sendiri juga hubungan sosial dengan individu lain (Martin,2000 dalam Weny, 2016).

Faktor yang berasal dari dalam diri pegawai yang dapat mempengaruhi kinerja mereka dalam organisai sangat banyak diantaranya yaitu kecerdasan intelektual (IQ), kecerdasan emosional (EQ), kecerdasan spiritual (SQ) dan organizational citizenship behavior (OCB). Kecerdasan intelektual (IQ) bisa dimaknai, kecakapan seseorang dalam beradaptasi dengan lingkungan yang baru, dengan menggunakan media berpikir efektif untuk menggapai tujuan yang ingin dicapai (Ngalim, 2013:52; aderharda, 2018).

Kecerdasan intelektual (IQ) dapat berhasil dengan optimal jika diimbangi dengan kecerdasan emosional (EQ) dan kecerdasan spiritual (SQ). Kecerdasan emosional (EQ) diartikan sebagai suatu kesadaran diri, penguasaan diri, komitmen dan integrtas seseorang 
dan kemampuan seseorang dalam mengkomunikasikan, mempengaruhi, melakukan inisiasi perubahan (Fadliyansyah, 2012:6; aderharda, 2018). Kecerdasan spiritual (SQ) menurut Zohar dan Marshal (2012;23;dalam aderharda, 2018) menyatakan kecerdasan spiritual (SQ) mampu menjadikan manusia makhluk yang sepurna dari segi intelektual, emosional dan spiritual. Kecerdasan intelektual (IQ), kecerdasan emosional (EQ) dan kecerdasan spiritual (SQ) yang ada dalam diri pegawai akan sangat lengkap jika diimbangi dengan perilaku organiziational citizenship behavior (OCB). Menurut Organ, Podsakoff, dan MacKenzie (2006; dalam endah dan nur, 2018) menyatakan bahwa OCB sebagai kesukarelaan pegawai untuk berperan lebih dari porsi semestinya dalam suatu organisasi. OCB diharapkan bahwa pegawai dpaat bekerjasama dengan baik dengan lingkungan kerja dan juga dapat menjalin hubungan dengan rekan kerja sehingga dapat membentuk kerjasama yang baik guna menyeleseikan segala tugas dan tanggungjawab yang diberikan.

Sekretariat Daerah Kota Kediri berfungsi sebagai peran organisasi dan pelayanan yang berkaitan dengan teknis administrasi kepada seluruh perangkat yang berada dalam pemerintahan daerah sehingga evaluasi kinerja pegawai organisasi merupakan hal yang sangat pentimg untuk dilakukan secara berkala terutama untuk mengetahui hal apa saja yang dapat menghambat kinerja pegawai dan segara dapat melakukan perubahan yang lebih baik kedepannya demi terwujudnya tujuan organisasi. Penilaian kinerja pegawai yang dilakukan tidak hanya untuk terwujudnya tujuan organisasi melainkan juga berfungsi dalam penyesuaian anggaran organisasi (Renny, 2012). Salah stau unit kerja di Sekretariat Daerah Kota Kediri yang penting salah satunya adalah Bagian Umum, dimana menurut pasal 3 ayat (1) huruf d angka 1 mempunyai tugas menyiapkan perumusan kebijakan, mengkoordinasikan pelaksanan tugas dan fungsi, pemantauan dan evaluasi program kerja, penyelenggaraan pembinaan teknis, administrasi dan sumber daya urusan tata usaha, rumah tangga dan pemeliharaan Sekretariat Daertah Kepala Daerah, Wakil Kepala Daerah dan Staf Ahli. Tugas-tugas yang dimiliki oleh pegawai Bagian Umum merupakan tugas-tugas penting yang harus diseleseikan dengan efektif dan efeisien. Untuk mewujudkan hal tersebut diharapkan instansi mempu melakukan pengawasan dengan baik sehingga pegawai Bagian Umum dapat menjaga dan meningkatkan kinerja mereka.

Dalam praktiknya masih banyak pegawai yang kurang efektif dan efisien dalam menyelesikan tugas mereka, sikap pasif dalam menyelesikan masalah internal organisasi, kurangnya pengendalian emosi disaat banyaknya beban kerja yang harus diseleseikan, sulitnya menghargai rekan kerja dan menjalin kerjasama disaat berada dalam kisaran usia pencarian jati diri dalam berkarir merupakan fenomena yang umum sering terjadi pada pegawai Bagian Umum Sekretariat Kota Kediri. Paparan diatas membuat peneneliti tertarik untuk melakukan peninjauan lebih lanjut mengenai apakah pengaruh kecerdasan intelektual, kecerdasan emosional, kecerdasan spiritual dan organizatinal citizenship behavior dapat mempengaruhi kinerja pegawai.

Kecerdasan Intelektual (IQ) adalah keahlian seseorang dalam melakukan sesuatu dengan sistematis, rasional dan menghadapi lingkungan disekitar secara efektif. Kecerdasan Intelektual (IQ) juga bisa diartikan sebagai suatu kemampuan yang berhubungan dengan kecerdasan seseorang dalam mencari solusi suatu kasus secara matematis dan rasional, atau kemampuan kognitif yang dimiliki untuk beradaptasi secara efektif (Adam, Wispandono, Helmi,2019). Aspek-aspek yang terdapat dalam 
kecerdasan intelektual menurut Rona and Gan (2008; dalam Arshad MahmoodandMohdAnuarArshad, AdeelAhmed,, 2017) yaitu: (1) knowledge, (2) skills, (3) abilities

Kecerdasan Emosional (EQ) merupakan kemampuan untuk mengenali diri sendiri, orang lain, kemampuan memotivasi diri sendiri serta mampu untuk mengelola emosi secara bijak. Selain itu kecerdasan emosional dapat dimaknai sebagai kemampuan individu dalam mengontrol perasaan dan emosinya dengan baik sehingga berdampak positif untuk diri sendiri maupun orang lain, serta mampu untuk menggunakan informasi itu untuk membimbing pikiran dan tindakannya (Adam, Wispandono, Helmi, 2019). Aspek-aspek yang terdapat dalam kecerdasan intelektual menurut Rona and Gan (2008; dalam Arshad Mahmood and Mohd Anuar Arshad, Adeel Ahmed, 2017) yaitu: (1) emotional control, (2) stress management skills, (3) conflict management skills

Kecerdasan spiritual (SQ) merupakan keahlian untuk menghadapi dan mencari solusi, dan mempertimbangkan segala sesuatu makna dalam hidup melalui tindakan dan prinsip hidup (Adam, Wispandono, Helmi,2019). Aspek-aspek yang terdapat dalam kecerdasan intelektual menurut Rona and Gan (2008; dalam Arshad MahmoodandMohdAnuarArshad, AdeelAhmed,, 2017) yaitu: (1) Wisdom, (2) Spiritual vallue, (3) Trancendence, (4) Humanization, (5) Connectedness

Organizational Citizenship Behavior (OCB) menurut (Robbins dalam Yumna dan Hanifah, 2017) meripakan perilaku sukarela yang dilakukan oleh individu dalam lingkungan organisasi diluar sistem kerja formal, yang memiliki dampak postif dalam mendukung efektivitas organisasi, meskipun tanpa adanya kompensasi dan hukuman di dalamnya. Aspek-aspek OCB menurut Organ et all dalam Wrdhani dan Adji (2016) menyebutkan bahwa: (1) Altruism, (2) Civic virtue,(3) Conscientiousness Courtesy, (4) Sportsmanship

Anwar Prabu Mangkunegara dalam Yeni (2016) kinerja adalah hasil kerja yang dinilai dari kualitas dan kuantitas yang dilakukan oleh pegawai dalam melaksanakan tugas dan tanggungjawab yang dibebankan. Aspek-aspek kinerja menurut Bernadin dalam Yeni (2016) yaitu (1) Kualitas. (2) Kuantitas (3) Ketepatan waktu, (4) Efektifitas, (5) Kemandirian, (6) Komitmen

\section{METODE PENELITIAN}

Penelitian ini merupakan Explanatory Research yang merupakan penelitian untuk menguji hubungan antar variabel yang dihipotesis. Populasinya adalah 71 pegawai Bagian Umum Sekretariat Daerah Kota Kediri. Teknik pengambilan sampel menggunakan sampel jenuh dimana seluruh populasi digunakan sebagai subjek penelitian dengan menggunakan teknik analisa yang digunakan dalam penelitian ini analisa regresi linier berganda.

Pada penelitian ini terdapat tiga variabel bebas yaitu kecerdasan intelektual (X1), kecerdasan emosional (X2), kecerdasan spiritual (X3), dan organizational citizenshp behavior (X3) dan satu variabel terikat yaitu kinerja (Y). 


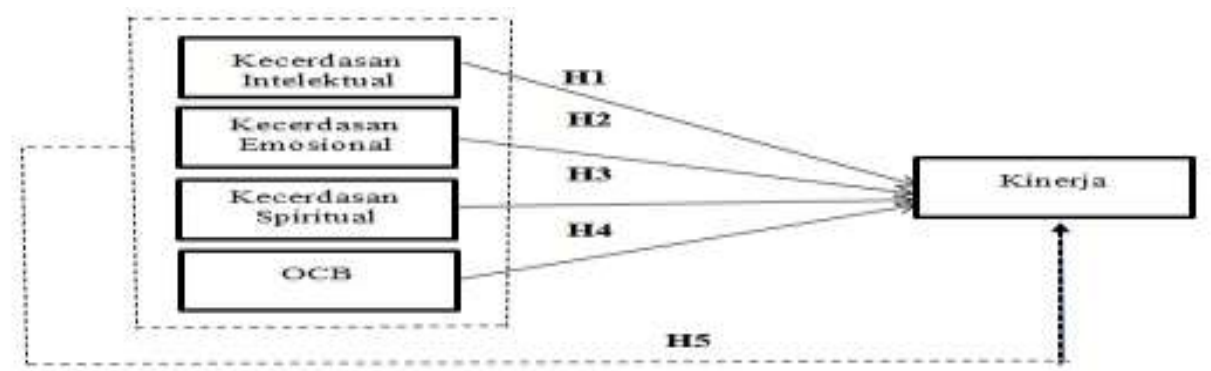

HASIL DAN PEMBAHASAN

Hasil Analisis Regresi Linier Berganda

\begin{tabular}{|c|c|c|c|c|c|}
\hline \multirow{2}{*}{\begin{tabular}{|c|} 
Variabel \\
Model
\end{tabular}} & \multicolumn{2}{|c|}{$\begin{array}{l}\text { Unstandardized } \\
\text { Coefficients }\end{array}$} & \multirow{2}{*}{$\begin{array}{c}\begin{array}{c}\text { Standart } \\
\text { Coefficients }\end{array} \\
\text { Beta }\end{array}$} & \multirow{2}{*}{$\mathbf{t}$} & \multirow{2}{*}{ Sig } \\
\hline & B & $\begin{array}{l}\text { Std. } \\
\text { error }\end{array}$ & & & \\
\hline (constant) & 9.475 & 1.595 & & 5.940 & 0.000 \\
\hline $\begin{array}{l}\text { Kecerdasan } \\
\text { Intelektual }\end{array}$ & 0.059 & 0.083 & 0.081 & 0.715 & 0.477 \\
\hline $\begin{array}{l}\text { Kecerdasan } \\
\text { Emosional }\end{array}$ & 0.209 & 0.086 & 0.256 & 2.444 & 0.017 \\
\hline $\begin{array}{l}\text { Kecerdasan } \\
\text { Spiritual }\end{array}$ & 0.046 & 0.096 &., 051 & 0.475 & 0.637 \\
\hline $\mathrm{OCB}$ & 0.377 & 0.095 & 0,539 & 3.987 & 0.000 \\
\hline \multicolumn{6}{|c|}{$\mathrm{R}=0.871$} \\
\hline \multicolumn{2}{|c|}{ R Square } & \multicolumn{4}{|c|}{$=0.758$} \\
\hline \multicolumn{2}{|l|}{ Adjusted R Square } & \multicolumn{4}{|c|}{$=0.743$} \\
\hline \multicolumn{2}{|l|}{$\mathrm{F}$} & \multicolumn{4}{|c|}{$=51.708$} \\
\hline \multicolumn{2}{|c|}{$\operatorname{Sig} F$} & \multicolumn{4}{|c|}{$=0.000$} \\
\hline \multicolumn{2}{|c|}{ Std Error of the estimate } & \multicolumn{4}{|c|}{$=1.152$} \\
\hline
\end{tabular}

Sumber: data primer diolah, 2021

\section{1) Pengaruh Kecerdasan Intelektual (IQ) Terhadap Kinerja}

Berdasarkan hasil pengujian menunjukkan bahwa kecerdasan intelektual tidak berpengaruh secara parsial terhadap kinerja Pegawai Bagian Umum Sekretariat Daerah Kota Kediri. Hal ini dibuktikan dengan nilai sig $0.477<$ 0.05. Tugas pokok Pegawai Bagian Umum Sekretariat Daerah Kota Kediri adalah melakukan sebagian tugas Sekretaris Daerah dalam penyiapkan bahan perumusan kebijakan dibidang urusan rumah tangga, serta melakukan tugastugas lain yang diberikan oleh Asisten Administrasi sesuai bidang tugasnya. Tugas-tugas tersebut merupakan tugas yang dalam pengerjaannya tidak perlu menonjolkan kecerdasan intelektual secara aktif seperti memberikan ide atau gagasan dalam penentuan kebijakan-kebijakan.

1266 AKSARA: Jurnal Ilmu Pendidikan Nonformal 
AKSARA: Jurnal Ilmu Pendidikan Nonformal

P-ISSN 2407-8018 E-ISSN 2721-7310 DOI prefix $\underline{10.37905}$

Volume 07, (03) September 2021

http://ejurnal.pps.ung.ac.id/index.php/Aksara

\section{2) Pengaruh Kecerdasan Emosional (EQ) Terhadap Kinerja}

Berdasarkan hasil pengujian menunjukkan bahwa kecerdasan emosional berpengaruh terhadap kinerja Pegawai Bagian Umum Sekretariat Daerah Kota Kediri. Hal ini dibuktikan dengan nilai sig $0.017<0.05$. Dalam melaksanakan segala tanggungjawab sebagai Pegawai Bagian Umum, dimana dalam pekerjaannya sangat diperlukan loyalitas dan dedikasi yang tinggi, maka sangat diharuskan pegawai Bagian Umum mampu mengelola emosi mereka dengan baik agar tugas-tugas yang diberikan bisa diseleseikan sesuai dengan standar yang telah ditetapkan. Selain pengelolaan emosi yang baik, mereka juga harus mempunyai motivasi yang kuat dalam menyeleseikan tugas dan tanggungjawab, sehingga tidak ada pekerjaan yang tertunda, dan juga rasa empati yang besar terhadap rekan kerja, karena dalam menjalankan segala tugasnya mereka membutuhkan kerja sama yang baik.

\section{3) Pengaruh Kecerdasan Spiritual (SQ) Terhadap Kinerja}

Berdasarkan hasil pengujian menunjukkan bahwa kecerdasan spiritual tidak memiliki pengaruh terhadap kinerja Pegawai Bagian Umum Sekretariat Daerah Kota Kediri. Hal ini dibuktikan dengan nilai sig 0.637>0.05. Kecerdasan spiritual (SQ) merupakan kecerdasan yang dimiliki seseorang untuk mampu menyesuaikan diri dengan lingkungan dan memecahkan masalah yang berhubungan dengan nilai-nilai batin dan kejiwaan. Kecerdasan spiritual (SQ) yang dimiliki seseorang diharapkan mampu menumbuhkan semangat positif dalam melakukan kegiatan baik dalam kehidupan pribadi maupun kehidupan dalam organisasi. Namun pada kenyataanya, kecerdasan spiritual yang dimiliki oleh Pegawai Bagian Umum Kesekretariatan Daerah masih belum mampu meningkatkan kinerja pegawai, hal ini dikarenakan banyak dari pegawai yang masih berusia diantara 25-45 tahun dimana usiausia tersebut masih dalam rentan usia yang berada pada tahap pencarian kematangan dalam berpikir dan bertindak, masa produktif yang menempatkan jenjang karir dalam prioritas utama mereka saat bekerja. Sehingga bisa diartikan bahwa masa tersebut merupakan masa yang penuh dengan masalah, tantangan dan ketegangan baik itu secara pribadi maupun secara sosial dengan lingkungan dan rekan kerja.

\section{4) Pengaruh Organizational Citrizenship Behavior (OCB) Terhadap Kinerja} Berdasarkan hasil pengujian menunjukkan bahwa organizational citizenship behavior berpengaruh secara parsial terhadap kinerja Pegawai Bagian Umum Sekretariat Daerah Kota Kediri. Hal ini ditunjukksn dengan nilai sig $0.000<$ 0.05 . OCB mempunyai peran yang sangt penting bagi organisasi dalam mewujudkan tujuan yang diharapkan. hal ini juga berlaku pada staf bagian umum dimana dalam bekerja mereka selalu bersungguh-sungguh dalam menyeleseikan tanggungjawab mereka, karena mereka merasa harus melakukan pengabdian dengan penuh komitmen pada instansi tempat mereka bekerja. Mereka juga senantiasa membantu rekan kerja yang mendapat kesulitan dalam menyeleseikan tugas, sehingga tugas-tugas yang telah dijadwalkan bisa selesei tepat waktu. Selain itu antar rekan kerja saling 
menjaga hubunganb haik dalam rangka menjaga kekompakan sehingga dapat bekerja sama dengan baik untuk menyeleseikan tugas-tugas yang ada.

5) Pengaruh kecerdasan intelektual (IQ), kecerdasan emosional (EQ), kecerdasan spiritual (SQ) dan organizational citizenship behavior (OCB) terhadap kinerja

Berdasarkan hasil pengujian menunjukkan bahwa kecerdasan intelektual, kecerdasan emosional, kecerdasan spiritual dan organizational citizenship behavior memiliki pengaruh secara simultan terhadap kinerja Pegawai Bagian Umum Sekretariat Daerah Kota Kediri. Hal tersebut ditunjukkan dengan nilai sig $0.000<0.05$. Pengaruh secara simultan ini juga bisa ditunjukkan dengan nilai koefisien korelasi bernilai positif sebesar 0,971 dan nilai koefisien sebesar 0,758 yang berarti kecerdasan intelektual, kecerdasan emosional, kecerdasan spiritual dan organizational citizenship behavior bekerja secara bersama-sama mempengaruhi kinerja sebesar 75,8\% dan $24,2 \%$ adalah pengaruh lain di luar penelitian. Semakin baik kecerdasan intelektual, kecerdasan emosional, kecerdasan spiritual dan organizational citizenship behavior maka akan baik juga kinerja Pegawai Bagian Umum yang bekerja di Kantor Sekretariat Daerah Kota Kediri, sehingga bisa memberikan kontribusi yang maksimal dalam mewujudkan tujuan organisasi.

\section{KESIMPULAN}

1. Kecerdasan intelektual tidak memiliki pengaruh secara parsial terhadap kinerja Pegawai Bagian Umum pada Kantor Sekretariat Daerah Kota Kediri. Hal ini ditunjukkan dengan nilai sig $0.477>0.05$.

2. Kecerdasan emosional memiliki pengaruh secara parsial terhadap kinerja Pegawai Bagian Umum pada Kantor Sekretariat Daerah Kota Kediri. Hal ini ditunjukkan dengan nilai sig $0.017<0.05$.

3. Kecerdasan spiritual tidak memiliki pengaruh secara parsial terhadap kinerja Pegawai Bagian Umum pada Kantor Sekretariat Daerah Kota Kediri. Hal ini ditunjukkan dengan nilai sig $0.637<0.05$.

4. Organizational citizenship behavior memiliki pengaruh secara parsial terhadap kinerja Pegawai Bagian Umum pada Kantor Sekretariat Daerah Kota Kediri. Hal ini ditunjukkan dengan nilai sig $0.000<0.05$.

5. Kecerdasan intelektual, kecerdasan emosional, kecerdasan spiritual dan organizational citizenship behavior memiliki pengaruh secara simultan terhadap kinerja Pegawai Bagian Umum pada Kantor Sekretariat Daerah Kota Kediri. Hal ini ditunjukkan dengan nilai sig $0.000<0.05$.

\section{SARAN}

Berdasarkan dari hasil penelitian yang telah dilakukan terhadap pegawai Bagian Umum Sekretariat Daerah Kota Kediri, yaitu:

1) Diharapkan Pegawai Bagian Umum Sekretariat Daerah Kota Kediri mengasah kecerdasan intelektual dalam berbagai permasalahan yang berkaitan dengan pekerjaan maupun dengan lingkungan tempat mereka bekerja. Untuk mengatasi 
permasalahan tersebut maka perlu dikembangkan hal yang berkaitan dengan kecerdasan intelektual salah satunya dengan mengadakan workshop.

2) Sekretariat Daerah terutama Bagian Umum hendaknya melakukan pelatihan tentang pentingnya optimalisasi EQ dan SQ dalam berkerja agar kinerja pegawai meningkat, agar pegawai mampu mengenali emosi diri yang ada di dalam diri mereka, mampu mengendalikan emosi disaat bekerja, mampu berempati terhadap rekan kerja, mampu menyesuaikan diri dengan segala aturan yang ada, mampu menerapkan nilai-nilai spiritual dalam pelaksanaan tugas dan tanggungjawab, serta bisa berpikit dengan bijaksana dalam menghadapi segala sesuatu.

3) Untuk meningkatkan organizational citizenship behavior dalam instansi memang bukanlah hal yang mudah dikarenaka ocb muncul atas dasar kemauan pribadi pegawai, namun hal tersebut bukan merupakan hambatan bagi instansi untuk tidak mewujudkan ocb yang optimal. Pemberian contoh yang bisa dilakukan oleh Kepala Bagian umum seperti selalu mendengarkan saran dari bawahan, selalu terbuka jika diajak berdiskusi, dan tidak segan untuk membantu bawahan yang sedang mengalami kesulitan dalam menyeleseikan tugas-tugas mereka.

\section{DAFTAR PUSTAKA}

Anwar, A., \& Rahman, M. S. (2018). E ff ects of spiritual intelligence from Islamic perspective on emotional intelligence. (1983). https://doi.org/10.1108/JIABR-10$\underline{2016-0123}$

Arif,B. Dea,P (2014).Does Job Satisfaction Influence Organizational Citizenship Behavior?: An Empirical Study In Selected 4-Star Hotels In Jakarta, Indonesia. Society of Interdisciplinary Business Research \& Universiti Kuala Lumpur Business School Paper ID \# KL14-046, February 7-8, 2014, Kuala Lumpur, Malaysia

Dries, N., Pepermans, R., Dries, N., \& Pepermans, R. (2008). Using emotional intelligence to identify high potential: a metacompetency perspective. https://doi.org/10.1108/01437730710835470

Firdaus, A., Wispandono, M., \& Buyung, H. (2019). Pengaruh Kecerdasan Intelektual, Kecerdasan Emosional Dan Kecerdasan Spirritual Terhadap Kinerja Pegawai (Studi Pada Kantor Kecamatan Kabupaten Bangkalan). Eco-Entrepreneurship, 5(1), 1732.

Gujarati, N.Damodar.Basic Econometrics.New York:Mc.Graw-Hill.2003

Hakim, W., \& Fernandes, A. (2017). Journal of Organizational Change Management Moderation effect of organizational citizenship behavior on the performance of lecturers For Authors Moderation effect of organizational citizenship behavior on the performance of lecturers. Journal of Organizational Change Management, 112016. Retrieved from https://doi.org/10.1108/JOCM-11-2016-0242 
Hasibuan, Malayu S.P., (2014). Manajemen Sumber Daya Manusia. Edisi Revisi, cetakan kedelapan belas, Jakarta: Penerbit PT Bumi Aksara.

John P Mayer and Natalie J Allen. 1990. Themeasurement and antecedents of affective, continuance and normativecommitmenttotheorganization. Journal of Occupational Psychology: The British PsychologicalSociety

Lestari, E. R., \& Ghaby, N. K. F. (2018). Pengaruh Organizational Citizenship Behavior (OCB) Terhadap Kepuasan Kerja dan Kinerja Karyawan. Industria: Jurnal Teknologi Dan Manajemen Agroindustri, 7(2), 116-123.

Luthan, F., 2002.Organization Behavior. Eight Edition. McGraw Hill International edition. Singapore.Mc Cue, Jacques and RousselGianakis, 2001.A Study of the Relationships between Compensation Package, Work Motivation and Job Satisfaction.Journal of Organizational Behavior.20, 1003-1025.

Mahmood, A., Arshad, M. A., \& Ahmed, A. (2018). Spiritual intelligence research within human resource development: a thematic review. 41(8), 987-1006. https://doi.org/10.1108/MRR-03-2017-0073

Mohammad, J., Habib, F. Q., \& Alias, M. A. (2011). Job Satisfaction and Organizational Citizenship Behavior: An Empirical Study at Higher Learning Institutions. Asian Academy of Management Journal , 6 (2), 149-165.

Mowday, R.T., Porter, L.W., \& Steers, R.M. 2002.Employee-organization linkages: The psychology of commitment, absenteeism, and turnover. New York: Academic Press.

Nurliani, Sunaryo, H., \& Slamet, A. R. (2019). Pengaruh Kecerdasan Intelektual, Kecerdasan Emosional, dan Kecerdasan Spiritual, Terhadap Kinerja Karyawan (Pada Karyawan Non Medis Rumah Sakit Islam Malang UNISMA). 55-65.

Organ, Denis .1988. THE MOTIVATION BASIS OF ORGANIZATIONAL CITIZENSHIP BEHAVIOR, IN RESEARCH IN ORGANIZATIONAL BEHAVIOR.Vol,12.Barry M Staw dan Lawrence L Cumming, Eds.Greenwich, CT:JAI Press, 43-72.

Peraturan Walikota Kediri No. 28 Tahun 2019 tentang Kedudukan, Susunan Organisasi, Tugas Dan Fungsi Serta Tata Kerja Sekretariat Daerah

Permendagri No 12 Tahun 2008 tentang Pedoman Analisis Beban Kerja di Lingkungan Departemen Dalam Negeri dan Pemerintah Daerah. https://www.kemendagri.go.id/arsip/7/peraturan-mendagri.

Putri, Y., \& Utami, H. (2017). PENGARUH ORGANIZATIONAL CITIZENSHIP BEHAVIOR (OCB) TERHADAP KINERJA (Studi Pada Tenaga Perawat Ruang Rawat Inap Rumah Sakit Baptis Batu). Jurnal Administrasi Bisnis S1 Universitas Brawijaya, 46(1), 27-34. 
Puspita Dyah, Rusdarti. PENGARUH KOMITMEN ORGANISASI, KEPUASAN KERJA DAN BUDAYA ORGANISASI TERHADAP ORGANIZATIONAL CITIZENSHIP BEHAVIOR (OCB),(Studi pada PT. Plasa Simpanglima Semarang). JURNAL ILMIAH DINAMIKA EKONOMI DAN BISNIS Vol. 1 No. 1 April 2013

Prabu Mangkunegara, Anwar (2014). Evaluasi Kinerja SDM, Bandung : Penerbit PT Refika Aditama.

Priyono, (2008). Metode Penelitian Kuantitatif. Sidoarjo : Zifatama Publishing

Putri, Y. S. (2016). Emosional, Dan Lingkungan Kerja Terhadap. Jurnal Studi Manajemen \& Organisasi 13, 13, 88-97.

Schmidt, S. W. (n.d.). The Relationship Between Satisfaction with Workplace Training and Overall Job Satisfaction. 18(4). https://doi.org/10.1002/hrdq

Sibasopait, A. B. (2018). Pengaruh Kecerdasan Intelektual, Kecerdasan Emosional, Dan Kecerdasan Spiritual Terhadap Kinerja Melalui Kepuasan Kerja Tenaga Kependidikan Di Kantor Pusat Universitas Jember. Bisma, 12(2), 212. https://doi.org/10.19184/bisma.v12i2.7891

Siregar, Syofian, 2017. Metode Penelitian Kuantitatif Dilengkapi Dengan Perbandingan Perhitungan Manual \& SPSS. Jakarta : Kencana.

Smith, A. 1983. Organizational citizenship behavior: Its nature and antecedents. Journal of Applied Psychology, 68(4), 653-663.

Sugiyono, (2018). Metode Peelitian Kuantitatif, Kualitatif dan R\&D, Bandung: Penerbit Alfabeta.

Rahma Andala, Mizar Fauzi The Effect of Job Satisfaction and Organizational Justice on Organizational Citizenship Behavior with Organization Commitment as the Moderator. International Journal of Humanities and Social Science. Vol. 4, No. 9; July 2014. Faculty of Economics and Business University of Bandar Lampung

Riedel, Anggia G.C.R dkk, (2019). Pengaruh Human Relation, Job Satisfaction dan Job Description terhadap Kinerja Karyawan Manado Quality Hotel. Jurnal EMBA Vol. 7 No. 3 Juli 2019, Universitas Sam Ratulangi Manado.

Robbins, Stephen.P. 2006.Perilaku Organisasi. Edisi Kesepuluh. PT. Indeks Kelompok Gramedia.Jakarta

Robbins, Stephen P DAN Judge, Timothy (2008).Perilaku Organisasi, Buku 2.Jakarta:Salemba Empat 
AKSARA: Jurnal Ilmu Pendidikan Nonformal

P-ISSN 2407-8018 E-ISSN 2721-7310 DOI prefix $\underline{10.37905}$

Volume 07 (03) September 2021

http://ejurnal.pps.ung.ac.id/index.php/Aksara 